\title{
KELAYAKAN USAHATANI JAGUNG (Zae Mays L.) DI LAHAN TADAH HUJAN DESA GENENGSARI KECAMATAN POLOKARTO
}

\author{
Umi Nur Solikah ${ }^{1}$, Tria Rosana Dewi ${ }^{2}$, Abdul Bashir ${ }^{3}$ \\ ${ }^{1,2}$ Program Studi Agribisnis, Fakultas Pertanian UNIBA \\ ${ }^{3}$ BPP Kecamatan Polokarto, Kabupaten Sukoharjo \\ E-mail: ${ }^{1}$ umi_solikah@yahoo.co.id, ${ }^{2}$ triardewi@yahoo.co.id, \\ bashirchan123@gmail.com
}

\begin{abstract}
ABSTRAK
Indonesia adalah negara agraris yang mayoritas penduduknya hidup dibidang pertanian. Pertanian merupakan sektor yang mampu menopang sektor pembangunan dan meyumpang pendapatan nasional yang cukup besar. Salah satu komoditas pengan yang mempunyai peran stategis adalah jagung, permintaan terhadap jagung dari tahun ke tahun juga mengalami peningkatan. Tujuan penelitian ini adalah untuk mengetahui biaya, pendapatan dan kelayakan usahatani usahatani jagung (Zae Mays L.) di lahan tadah hujan. Metode analisis yang digunakan sebagai berikut, total biaya dihitung dengan menjumlahkan biaya tetap dengan biaya variabel, penerimaan dihitung dengan mengalikan harga produk dengan jumlah produk, pendapatan dapat dihitung dengan mengurangi total penerimaan dengan biaya total, $\mathrm{R} / \mathrm{C}$ rasio dapat dihitung dengan membandingkan antara total penerimaan dengan total biaya. Biaya total usahatani jagung di lahan tadah hujan dengan luas 0,4 Ha per garapan sebesar Rp. 4.257.071,-. Penerimaan usahatani jagung Rp. 6.240.000,-. Tingkat pendapatan usahatani jagung sebesar Rp.1.982.929,--. Kelayakan usahatani jagung sebesar 1,46 artinya hal ini berarti perbandingan menghasilkan nilai di atas nilai 1 ( $\mathrm{R} / \mathrm{C}$ rasio $>1)$, artinya kegiatan usahatani jagung layak diusahakan karena usahatani jagung memperoleh keuntungan yang ekonomis bagi petani.
\end{abstract}

Kata Kunci: Kelayakan, Usahatani, Jagung, Tadah hujan

\section{ABSTRACT}

Indonesia is an agricultural country where the majority of the population lives in agriculture. Agriculture is a sektor that is able to support the development sektor and support a fairly large national income. One of the confectionery commodities that has a strategic role is corn, the demand for corn from year to year also increases. The purpose of this study was to determine the cost, income and feasibility of farming corn (Zae Mays L.) in rainfed land. The analytical method used is as follows, total costs are calculated by adding up fixed costs with variable costs, revenue is calculated by multiplying product prices by the number of products, revenue can be calculated by subtracting total revenues from total costs, $R / C$ ratio can be calculated by comparing the total revenues with the total cost. The total cost of farming corn in rainfed land with an area of 0.4 ha per arable is Rp. 4.257.071,-- Revenue from corn farming $R p$. 6.240.000,-. The income level of corn farming is $R p$. 1,982,929,-. The feasibility of farming corn is 1.46, meaning that this means that the comparison produces a value above the value of $1(R / C$ ratio $>1)$, meaning that maize farming activities are feasible because maize farming obtains economic benefits for farmers. 


\section{PENDAHULUAN}

Indonesia adalah negara agraris yang mayoritas penduduknya hidup di bidang pertanian. Pertanian merupakan sektor yang mampu menopang sektor pembangunan dan meyumpang pendapatan nasional yang cukup besar. Salah satu komoditas pengan yang mempunyai peran stategis adalah jagung. Menurut (Sudayana, 2005) beberapa tahun terakhir kebutuhan jagung terus meningkat, hal ini sejalan dengan semakin meningkatnya laju pertumbuhan jumlah penduduk dan peningkatan kebutuhan untuk pakan.

Selain untuk pangan, jagung juga banyak digunakan untuk pakan ternak dan bahan baku industri. Menguatnya kurs dolar berpengaruh langsung terhadap kenaikan harga jagung impor, sehingga turut pula memicu kenaikan harga pakan ternak. Kondisi ini tentunya cukup menggoyahkan sektor peternakan. Sebagian peternak terpaksa gulung tikar karena keuntungan yang diperoleh tidak sebanding dengan harga pakan. Oleh karena itu, peningkatan produksi jagung perlu mendapat perhatian lebih besar, baik melalui perluasan areal, penggunaan variateas unggul maupun perbaikan teknis budidaya maupun pasca panen (Suprapto, 2002).

Upaya peningkatan produksi jagung di dalam negeri dapat ditempuh melalui perluasan areal tanam dan peningkatan produktivitas. Perluasan areal dapat diarahkan pada lahan-lahan potensial seperti lahan sawah irigasi, lahan sawah tadah hujan, dan lahan kering yang belum dimanfaatkan untuk pertanian (Anonim, 2015).

\section{METODOLOGI PENELITIAN 2.1 Waktu dan Tempat Penelitian}

Penelitian ini dilaksanakan pada bulan November 2019 sampai bulan Februari 2020. Lokasi penelitian di lakukan secara sengaja (purposive), dengan pertimbangan bahwa di Desa tersebut banyak diusahakan usahatani jagung.yaitu di Desa Genengsari, Kecamatan Polokarto, Kabupaten Sukoharjo,

\subsection{Penentuan Sample}

Jumlah populasi dalam penelitian ini sebanyak 75 petani. Pengambilan sample dilakukan dengan menggunakan metode simple random sampling yaitu suatu metode semua anggota sampel dianggap memiliki karakteristik yang sama sehingga siapapun yang diambil dapat mewakili populasinya (Mardikanto, 2006).

\subsection{Jenis Dan Sumber Data}

Data dalam penelitian ini meliputi data primer dan data sekunder

a. Data primer merupakan data yang diperoleh/ dikumpulkan secara langsung dari lapangan oleh peneliti. Data primer yang diambil antara lain wawancara dengan petani, mengenai semua biaya, penerimaan dan pendapatan dalam usahatani jagung

b. Data sekunder adalah data yang telah diolah dan diperoleh dari instansi pemerintah setempat atau dari pihak-pihak yang terkait, seperti data mengenai gambaran umum lokasi penelitian,

\subsection{Metode Analisis Data}

Tahapan analisis data dalam penelitian ini adalah sebagai berikut yaitu :

\section{a. Total Biaya}

Biaya usahatani jagung adalah pengeluaran - pengeluaran yang dilakukan oleh petani dalam usahatani 
jagung meliputi biaya sarana produksi (benih, pupuk, pestisida) tenaga kerja, transportasi, penyusutan alat, pajak tanah, dan sewa mesin pemipil (Rahayu, 2020).

Menurut Noor (2007), total biaya dihitung dengan rumus sebagai berikut:

$$
\mathrm{TC}=\mathrm{TFC}+\mathrm{TVC}
$$

Keterangan :

$\mathrm{TC}=$ Biaya total/ Total Cost

(Rp/Garapan)

TFC = Total Biaya Tetap/ Total Fixed

Cost (Rp/Garapan)

TVC = Total Biaya Variabel/ Total

Variable Cost (Rp/Garapan)

\section{b. Penerimaan}

Menurut Sukirno (2002), untuk mengetahui jumlah penerimaan yang diperoleh dapat diketahui dengan menggunakan rumus :

$$
\mathbf{T R}=\mathbf{P} \times \mathbf{Q}
$$

Keterangan :

$\mathrm{TR}=$ Total Penerimaan/ Total revenue (Rp/Garapan)

$\mathrm{P}=$ Harga Produk / Price

(Rp/Garapan)

$\mathrm{Q}=$ Jumlah Produk / Quantity

(Rp/Garapan)

\section{c. Pendapatan}

Menurut Mubyarto (1994), pendapatan dihitung dengan cara mengurangkan total penerimaan dengan total biaya, dengan rumus sebagai berikut :

$$
\mathbf{I}=\mathbf{T R}-\mathbf{T C}
$$

Keterangan :

I = Pendapatan/Income (Rp/Garapan)

$\mathrm{TR}=$ Total penerimaan/Total revenue (Rp/Garapan)
$\mathrm{TC}=$ Biaya Total/Total cost

(Rp/Garapan)

\section{d. R/C rasio (Perbandingan Total Penerimaan dan Total Biaya)}

Menurut Noor, 2007, R/C Rasio adalah merupakan perbandingan antara total penerimaan dengan total biaya. Sehingga $\mathrm{R} / \mathrm{C}$ rasio dapat dirumuskan:

Keterangan

$$
R / C=T R / T C
$$

$\mathrm{TR}=$ Total Revenue (Total Penerimaan) (Rp/Garapan)

$\mathrm{TC}=$ Total Cost $($ Total Biaya)

(Rp/Garapan)

Kriteria Penerimaan $\mathrm{R} / \mathrm{C}$ ratio:

- $\mathrm{R} / \mathrm{C}<1=$ usahatani jagung dilahan tadah hujan mengalami kerugian

- $\mathrm{R} / \mathrm{C}>1=$ usahatani jagung dilahan tadah hujan memperoleh keuntungan

- $\mathrm{R} / \mathrm{C}=1=$ usahatani jagung dilahan tadah hujan mencapai titik impas

\section{HASIL DAN PEMBAHASAN}

\section{a. Biaya Usahatani}

Biaya usahatani jagung di lahan tadah hujan dengan luas garapan $4.000 \mathrm{~m}$ dapat dihitung dengan menggunakan rumus

$$
\text { TC }=\text { TFC }+ \text { TVC }
$$

Keterangan :

$\mathrm{TC}=$ Biaya total/ Total Cost

(Rp/Garapan)

TFC = Total Biaya Tetap/ Total Fixed

Cost (Rp/Garapan)

TVC = Total Biaya Variabel $/$ Total

Variable Cost (Rp/Garapan) 
Tabel 1. Rincian Biaya Tetap dan Biaya Variabel

\begin{tabular}{|c|c|c|c|}
\hline \multicolumn{2}{|r|}{ Komponen } & Jumlah & $\begin{array}{c}\text { Presentase } \\
(\%)\end{array}$ \\
\hline Biaya & 1. Pajak Bumi Dan Bangunan & Rp. 13.500,- & $0,32 \%$ \\
\hline Tetap & $\begin{array}{l}\text { 2. Penyusutan alat-alat pertanian } \\
\text { (cangkul, sabit) }\end{array}$ & Rp. 90.571,- & $2,12 \%$ \\
\hline \multicolumn{2}{|c|}{ Total biaya tetap } & Rp.104.071,-/garapan & $2,44 \%$ \\
\hline Biaya & a. Biaya saprodi & & \\
\hline \multirow[t]{6}{*}{ Variabel } & $\begin{array}{l}\text { 1. Benih jagung } 4 \mathrm{Kg} @ \text { Rp. } 60.000,- \\
\text { 2. Pupuk Kandang (pupuk organik) } 10\end{array}$ & Rp. 240.000,- & $5,64 \%$ \\
\hline & sak@ @p.15.000,- & Rp. 150.000,- & $3,53 \%$ \\
\hline & 3. Pupuk Anorganik : Urea (150 Kg @ & & \\
\hline & $\begin{array}{l}\text { Rp. 2.250/Kg), Phonska (150 Kg @ } \\
\text { Rp. 2.300,-)) }\end{array}$ & Rp. 780.000,- & $1832 \%$ \\
\hline & 4. Pestisida (reagent Rp.50.000,- & & \\
\hline & Dupon Rp.15.000,-) & Rp. 65.000,- & $1,53 \%$ \\
\hline \multirow[t]{15}{*}{ Total Bia } & & Rp.1.235.000,-/garapan & $29,02 \%$ \\
\hline & b. Tenaga Kerja & & \\
\hline & 1. Pengolahan tanah (traktor) & Rp. 300.000,- & $7,05 \%$ \\
\hline & $\begin{array}{l}\text { 2. Membuat Parit (3 Orang @ Rp. } \\
80.000,-)\end{array}$ & Rp. 240.000,- & $5,64 \%$ \\
\hline & 3. Tanam Jagung (5 Orang @ Rp. & & \\
\hline & $40.000,-)$ & Rp. 200.000,- & $4,70 \%$ \\
\hline & 4. Penyemprotan (2x @ Rp. 80.000,-) & Rp. 160.000,- & $3,75 \%$ \\
\hline & $\begin{array}{l}\text { 5. Potong Daun Bawah Tongkol } \\
\text { Jagung (4hari @Rp. 80.000,-) }\end{array}$ & Rp. 320.000,- & $7,52 \%$ \\
\hline & $\begin{array}{l}\text { 6. Potong Daun Atas Tongkol Jagung } \\
\text { (7 Orang @ Rp.60.000,-) }\end{array}$ & Rp. 420.000,- & $9,86 \%$ \\
\hline & $\begin{array}{l}\text { 7. Panen Tongkol Jagung (7 Orang } \\
@ \text { Rp. } 60.000,-)\end{array}$ & Rp. 420.000,- & $9,86 \%$ \\
\hline & 8. Pengangkutan Panen Jagung & Rp. 100.000,- & $2,35 \%$ \\
\hline & 9. Penjemuran Jagung & Rp. 300.000,- & $7,05 \%$ \\
\hline & 10. Penjualan Jagung (transport dan & & \\
\hline & Tenaga Angkutan) & Rp. 140.000,- & $3,29 \%$ \\
\hline & 11. Biaya Pipil Jagung & Rp. 318.000,- & $7,47 \%$ \\
\hline \multicolumn{2}{|c|}{ Total Biaya } & Rp.2.918.000,-/garapan & $68,54 \%$ \\
\hline \multicolumn{2}{|c|}{ Total biaya tetap dan biaya variabel } & Rp. 4.257.071,- & $100 \%$ \\
\hline
\end{tabular}

Sumber: Analisis Data Primer, 2021

Dalam setiap proses produksi usahatani yang dilakukan, ada dua macam biaya dalam usahatani yaitu biaya tetap dan biaya variabel.

Menurut Ashari (2020), Biaya tetap merupakan pengeluaran usahatani yang jumlahnya tetap pada berbagai tingkat output yang diproduksi. Biaya tetap meliputi pajak lahan, sewa lahan, serta penyusutan alat.

Biaya tetap merupakan biaya yang tidak dipengaruhi oleh besar kecilnya produksi. Biaya tetap dalam usahatani jagung di lahan tadah hujan 
dengan luas pergarapan $4.000 \mathrm{~m}$ sebesar Rp. 104.071,- meliputi pajak bumi dan bangunan (PBB) dan penyusutan alatalat pertanian (cangkul, sabit, spayer). Sedangkan biaya variabel merupakan bentuk pengeluaran usahatani yang jumlahnya berubah-ubah tergantung besarnya produksi. Biaya variabel meliputi biaya pembelian benih, pupuk, pestisida, serta biaya penggunaan tenaga kerja (Ashari, 2020).

Biaya variabel merupakan biaya yang besarnya kecilnya tergantung dari luas usahatani, semakin luas lahan yang diusahakan maka semakin besar beban biaya yang di keluarkan. Biaya variabel dalam usahatani jagung di lahan tadah hujan dengan luas garapan $4.000 \mathrm{~m}$ meliputi biaya saprodi dan biaya tenaga kerja. Berdasarkan penelitian yang dilakukan besarnya biaya variabel usahatani di lahan tadah hujan dengan luas per garapan $4.000 \mathrm{~m}$ sebesar Rp. 4.153.000,-

Biaya produksi total dapat dihitung dengan menjumlahkan biaya tetap dengan biaya variabel. Dari hasil penelitian usahatani jagung di lahan tadah hujan dengan luas per garapan 4.000m sebesar Rp. 4.257.071,-

\section{b. Penerimaan Usahatani}

Penerimaan usahatani jagung di lahan tadah hujan dengan luas per garapan $4.000 \mathrm{~m}$ dapat dihitung dengan menggunakan rumus

Keterangan :

$$
\mathbf{T R}=\mathbf{P} \times \mathbf{Q}
$$

$\mathrm{TR}=$ Total Penerimaan $/$ Total revenue (Rp/Garapan)

$\mathrm{P}$ = Harga Produk/Price (Rp/Garapan)

$\mathrm{Q}=$ Jumlah Produk/Quantity $(\mathrm{Kg})$
Tabel 2. Penerimaan Usahatani

\begin{tabular}{|c|c|}
\hline Uraian & Per luas garapan \\
\hline Harga $(\mathrm{Rp} / \mathrm{Kg})$ & Rp.3.900,- \\
\hline Produk (Kg) & $1.600 \mathrm{Kg}$ \\
\hline Penerimaan(Rp) & Rp.6.240.000,- \\
\hline \multicolumn{2}{|c|}{ Sumber:Analisis Data Primer, 2021} \\
\hline \multicolumn{2}{|c|}{ 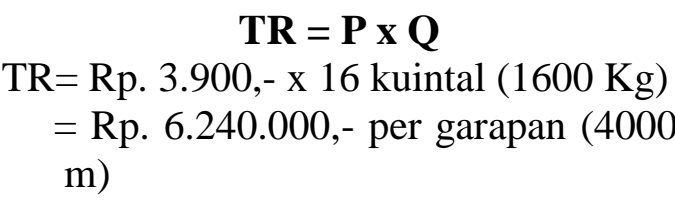 } \\
\hline
\end{tabular}

Husni, et al, (2014), penerimaan dalam usahatani adalah total pamasukan yang diterima oleh produsen atau petani dari kegiatan produksi yang sudah dilakukan yang telah menghasilkan uang yang belum dikurangi oleh biayabiaya yang dikeluarkan selama produksi. Total penerimaan yang diterima oleh petani dalam satu kali musim tanam sebanyak 16 kuintal $(1600 \mathrm{Kg})$ jagung pipil kering dengan harga per Kg Rp.3.900,- adalah sebesar Rp. 6.240.000,-

Penelitian Yuliana (2018) tentang analisis kelayakan usahatani jagung (Studi kasus: Desa Payabakung, Kecamatan Hamparan Perak, Kabupaten Deli Serdang) menunjukan bahwa penerimaan usahatani jagung diperoleh $\mathrm{Rp}$ 12.255.000,- dengan produksi $4085 \mathrm{Kg}$ / garapan dan tingkat harga Rp.3.000/Kg. Dari data menunjukan bahwa analisis kelayakan usahatani jagung (Studi kasus: Desa Payabakung, Kecamatan HamparanPerak, Kabupaten Deli Serdang) menunjukan bahwa penerimaan lebih besar karena luas garapan yang diusahakan lebih luas dan produksi yang dihasilkan juga lebih banyak. 
c. Pendapatan Usahatani Jagung (Zae Mays L.) di Lahan Tadah Hujan Dengan Luas Garapan 4.000 $\mathrm{M}^{2}$

Menurut Tomy (2013), pendapatan bersih usahatani adalah jumlah penerimaan usahatani dkurangi dengan jumlah pengeluaran usahatani. Pendapatan bersih ini merupakan imbalan dan jerih payah petani dan keluarganya dalam mengelola usahatani.

Pendapatan di dalam usahatani dibagi menjadi dua, yaitu pendapatan kotor dan pendapatan bersih. Pendapatan kotor adalah pendapatan yang belum dikurangi dengan biaya produksi atau yang biasanya disebut dengan penerimaan. Pendapatan bersih adalah pendapatan yang sudah dikurangi oleh biaya produksi (Tumoka, 2013).

Pendapatan usahatani jagung dapat dihitung dengan menggunakan rumus:

$$
\mathbf{I}=\mathbf{T R}-\mathbf{T C}
$$

Keterangan :

I =Pendapatan/Income (Rp/Garapan)

$\mathrm{TR}=$ Total penerimaan $/$ Total revenue (Rp/Garapan)

$\mathrm{TC}=$ Biaya $\quad$ Total/Total cost (Rp/Garapan)

Tabel.3 Pendapatan Usahatani

\begin{tabular}{ll}
\hline Uraian & Luas Per Garapan \\
\hline Total & Rp. 6.240.000,- \\
Penerimaan & \\
Total Biaya & Rp. 4.257.071,-- \\
Pendapatan & Rp.1.982.929,--
\end{tabular}

Sumber: Analisis Data Primer, 2021

$$
\begin{aligned}
\mathrm{I} & =\text { Rp. } 6.240 .000-\text { Rp. } 4.257 .071 \\
& =\text { Rp.1.982.929,- }
\end{aligned}
$$

Menurut Sukirno (2002), pendapatan diperoleh dengan cara menjumlahkan seluruh pendapatan yang diterima. Total pendapatan bersih dalam usahatani jagung di lahan tadah hujan dengan luas garapan $4.000 \mathrm{~m}$ sebesar Rp.1.982.929,-

Perangin (1999) dalam penelitiannya tentang analisis pendapatan usahatani dan pemasaran jagung menunjukkan bahwa rata-rata pendapatan usahatani jagung di daerah penelitian sebesar Rp. 3.420.500,00 dengan tingkat produksi 4,2 ton per hektar dan harga rata-rata sebesar Rp. $1.040,00$ per kilogram. Hal ini membuktikan bahwa luas lahan, tenaga kerja, jumlah produksi sangat mempengaruhi pendapatan petani.

Besar kecilnya luas lahan sangat berpengaruh terhadap produksi pertanian dan pendapatan usahatani. Jumlah tenaga kerja yang digunakan akan berpengaruh kepada pendapatan usahatani, jika jumlah tenaga kerja luar keluarga banyak digunakan akan memperbesar biaya variabel yang dkeluarkan oleh petani. Semakin besar jumlah produksi yang dihasilkan akan semakin banyak jumlah pendapatan yang dterima.

\section{d. Kelayakan usahatani jagung di lahan tadah hujan dengan luas 0,4 Ha \\ $\mathrm{R} / \mathrm{C}=\mathrm{TR} / \mathrm{TC}$ $=$ Rp. 6.240.000/ Rp. 4.257.071 $=1,46$ \\ Efisiensi merupakan upaya} untuk mencapai tujuan dengan meminimalkan atau menggunakan sumberdaya yang seoptimal untuk mencapai tujuan yang maksimal (Husni,et al, 2014).

Besarnya R/C Ratio pada usahatani jagung di lahan tadah hujan sebesar 1,46 yang berarti bahwa usahatani tersebut layak atau menguntungkan, dapat diartikan bahwa setiap biaya produksi yang dikeluarkan pada usahatani jagung sebesar 1,00 
maka akan memperoleh penerimaan sebesar 1,46.

\section{IV.PENUTUP}

\subsection{Kesimpulan}

Berdasarkan analisis yang telah dilakukan dapat diambil kesimpulan:

1. Biaya total yang dikeluarkan dalam usahatani jagung di lahan tadah hujan dengan luas garapan $4.000 \mathrm{~m}^{2}$ sebesar Rp. 4.257.071,-

2. Besarnya penerimaan usahatani jagung di lahan tadah hujan dengan luas garapan $4.000 \mathrm{~m}^{2}$ sebesar $\mathrm{Rp}$. 6.240.000,-

3. Tingkat pendapatan usahatani jagung di lahan tadah hujan dengan luas garapan $4.000 \mathrm{~m}^{2}$ sebesar Rp.1.982.929,-

4. Kelayakan usahatani jagung di lahan tadah hujan dengan luas garapan $4.000 \mathrm{~m}^{2}$ sebesar 1,46 artinya Hal ini berarti perbandingan menghasilkan nilai di atas nilai 1 $(\mathrm{R} / \mathrm{C}$ rasio > 1), artinya kegiatan usahatani jagung layak diusahakan karena usahatani jagung memperoleh keuntungan yang ekonomis bagi petani.

\subsection{Saran}

1. Petani perlu mencoba menerapkan sistem tanam jajar legowo karena dengan jajar legowo dapat meningkatkan penerimaan intensitas cahaya matahari pada daun dan diharapkan hasil asimilasi meningkat sehingga pengisian biji dapat optimal dan memudahkan pemeliharaan tanaman, terutama penyiangan gulma baik secara manual maupun dengan herbisida, pemupukan, serta pemberian air.

2. Petani perlu dibekali ilmu penanganan pasca panen untuk mendapatkan jagung yang bermutu tinggi dan menekan kehilangan hasil. Penanganan yang kurang baik akan menyebabkan kerusakan biji sehingga menurunkan mutu dan harga jagung.

\section{DAFTAR PUSTAKA}

Anonim. 2015. Pengelolaan Air Dalam Budidaya Jagung. https://tabloidsinartani.com/detail/in deks/mimbar-penyuluhan/2058pengelolaan-air-dalam-budidayajagung. Diakses Tanggal 18 Mei 2020.

Arifah, Eka Nur. 2011. Skripsi (Analisis Efisiensi Ekonomi Penggunaan Faktor-Faktor Produksi pada usahatani jagung varietas Bisi-2 Di Kabupaten Bantul). Fakultas Pertanian Universitas Sebelas Maret. Surakarta.

Ashari, Ulfira. 2020. Analisis Pendapatan dan Kelayakan Usahatani Jagung di Kecamatan Patilanggio Kabupaten Pohuwato Provinsi Gorontalo. Prosiding Seminar Nasional Pembangunan dan Pendidikan Vokasi Pertanian Politeknik Pembangunan Pertanian Manokwari. eISSN:2774-1982

Husni, a., k. Hidayah, Maskan. 2014. Analisis Finansial Usahatani Cabai Rawit (Capsicum Frutescens) Di Desa Purwajaya Kecamatan LoaJjanan. Jurnal Arifor. 13 (1). Universitas 17 Agustus 1945 Samarinda.

Mardikanto, Totok. 2006. Prosedur Penelitian Penyuluhan Pembangunan. Prima Pressindo. Surakarta.

Mubyarto. 1994. Pengantar Ekonomi Pertanian. Jakarta: LP3ES. Jakarta.

Noor, H., Faizal. 2007. Ekonomi Majerial. Raja Grafindo Persada. Jakarta. 
Parangin, Angin.1999. Skripsi (Analisis

Pendapatan Usahatani dan

Pemasaran Jagung). Departmen

Ilmu-Ilmu Sosial Ekonomi

Pertanian. Fakultas Pertanian.

Institut Pertaniaan Bogor.

Rahayu, wiwit, Umi Barokah, Rhina

Uchyani Fajarningsih. 2020.

Strategi Pengembangan Usahatani

Jagung Pada Lahan Kering Di

Kabupaten Wonosobo. AGRISEP

Vol. 19 No. 1 Maret 2020 Hal: 207 -218 .

Sadono, Sukirno. 2002, Pengantar Teori

Makroekonomi, edisi kedua, Rajawali Pers, Jakarta

Sudayana, Wayan. 2005. Perkembangan Jagung Pada Dekade Terakir Serta Peluang Pengembangan Ke Depan. SOCA. Vol.5, No.1 Februari 2005. https://ojs.unud.ac.id/index.php/soca /article/view/4069/3058. Diakses 18 Oktober 2021.
Sukirno, S. 2002. Pengantar Ekonomi Mikro. Edisi 3 Cetakan 17. Raja Grafindo Persada, Jakarta.

Suprapto dan Rasyid Marzuki. 2002. Bertanam Jagung. Penebar Swadaya. Jakarta.

Tomy, jonh. 2013. Analisis Produksi Dan Pendapatan Usahatani Jagung Di Kecamatan Palolo Kabupaten Sigi. Jurnal Agroland. Agustus 20 (2): 146-154.

Tumoka, N. 2013. Analisis pendapatan Usahatani Tomat di Kecamatan Kawangkoan Barat Kabupaten Minahasa. Jurnal EMBA. 1 (3)

Yuliana, Putri. 2018. Skripsi (analisis kelayakan usahatani jagung (zea mays L.) (Studi kasus: Desa Payabakung, Kecamatan HamparanPerak, Kabupaten Deli Serdang)). Universitas Muhammadyah Sumatra Utara. Medan 